\title{
BMJ Open Prevalence and correlates of sex- selective abortions and missing girls in Nepal: evidence from the 2011 Population Census and 2016 Demographic and Health Survey
}

\author{
Melanie Dawn Channon (D) , ${ }^{1}$ Mahesh Puri, ${ }^{2}$ Stuart Gietel-Basten (D) , \\ Lucy Williams Stone, ${ }^{4}$ A Channon ${ }^{5}$
}

To cite: Channon MD,

Puri M, Gietel-Basten S, et al. Prevalence and correlates of sex-selective abortions and missing girls in Nepal: evidence from the 2011 Population Census and 2016 Demographic and Health Survey. BMJ Open 2021;11:e042542. doi:10.1136/ bmjopen-2020-042542

- Prepublication history and additional materials for this paper is available online. To view these files, please visit the journal online (http://dx.doi org/10.1136/bmjopen-2020042542).

Received 08 July 2020 Revised 24 February 2021 Accepted 06 March 2021

Check for updates

(c) Author(s) (or their employer(s)) 2021. Re-use permitted under CC BY-NC. No commercial re-use. See rights and permissions. Published by BMJ.

For numbered affiliations see end of article.

Correspondence to Dr Melanie Dawn Channon; M.D.Channon@bath.ac.uk

\section{ABSTRACT}

Objectives These were to: (1) produce national and subnational estimates of the sex ratio at birth (SRB) and number of missing girl births in Nepal and (2) understand the socioeconomic correlates of these phenomena. Design Observational secondary data analysis of (1) the 2011 population census of Nepal and (2) the Nepal Demographic and Health Survey (DHS) 2006, 2011 and 2016.

Setting Nepal.

Participants (1) 2567963 children age 0-4 in the 2011 population census and (2) 27329 births recorded in DHSs. Primary and secondary outcomes We estimate the SRB, and number and proportion of missing girls in the year and 5 years before the census by district. We also calculate conditional sex ratios (the SRB dependant on parity and sex of previous children) by province, time, education and wealth.

Results We find that 11 districts have significantly skewed sex ratios at birth in the 2011 population census, with the highest SRBs observed in Arghakhanchi ( $\mathrm{SRB}=127$ ) and Bhaktapur (SRB=123). 22540 girl births were missing in the 5 years before the 2011 population census. Sex-selective abortion is geographically concentrated, especially in the Kathmandu Valley and Lumbini Province, with $53 \%$ of missing girls found in only 11 out of 75 districts.

DHS data confirm this, with elevated conditional sex ratios observed in Bagmati and Lumbini Provinces; conditional sex ratios where previous births were all female also became more skewed over time. Skewed sex ratios are concentrated among wealthier more educated groups. Conclusions It is clear that sex selection will persist and develop in Nepal unless a coordinated effort is made to address both the demand for and supply of this service. Policies should be holistic and encompass economic and legal gender equity, and strengthen monitoring mechanisms to prevent technology misuse, without jeopardising the right to safe, free and legal abortion.

\section{INTRODUCTION}

Skewed sex ratios at birth (SRBs) have now been part of the demographic landscape of

\section{Strengths and limitations of this study}

- Across Nepal, the numbers of boys born relative to girls are elevated, but we do not know how many girls are missing at birth nor district level variation-a gap in knowledge that this study rectifies.

- This study provides the first national and subnational estimates of the total number, and proportion of missing girl births in Nepal.

- This paper updates previous research that used older Demographic and Health Surveys to estimate sex ratios at birth and look at sociodemographic correlates of sex ratios at birth.

- Census data provide population-level information but lacks detail, while Demographic and Health Surveys include exceptional levels of detail with relatively small sample sizes.

- Sex-selective abortions are measured indirectly and rely on comparing the reported age and sex of births and young children, which may not always be accurate.

some Asian and European countries for over three decades. ${ }^{1}$ While the 'normal' human SRB is around 104-106 boys per 100 girls, since the development of ultrasound and other prenatal sex-determination technologies some countries have seen sex ratios well in excess of this. Multiple studies have identified skewed SRBs in China, ${ }^{2}$ Viet Nam, ${ }^{3}$ parts of Central Asia and Europe, ${ }^{4}$ as well as regions of India. ${ }^{56}$ In the past, skewed SRBs have been identified in other countries such as South Korea, ${ }^{7}$ which have since normalised.

There are a number of preconditions, which help explain why some countries experience skewed sex ratios while others do not: these were first proposed by Guilmoto in terms of a 'ready, willing and able' framework. ${ }^{1}$ The specific preconditions described were a persistent preference for sons (ready), 
falling fertility rates (willing) and access to prenatal sex determination technology (able). In the context of this framework, it is little wonder that Nepal may be experiencing increasing numbers of sex-selective abortions (SSA).

Son preference has a long history in Nepal, tied to the predominantly patrilineal and patrilocal society. In 2010, a small-scale ethnographic study in semiurban Nepal by Brunson found that young mothers 'reluctantly admit to needing a son'. ${ }^{8}$ Sons are regarded as economic assets and are highly sought after for continuing the family name, providing elderly care to parents, bringing a daughterin-law into the family and are integral to performing Hindu rituals such as funeral rites. ${ }^{8}$ Daughters, however, are often regarded as an economic burden because of the dowry system and the tradition of leaving their parents' family home to join the husband's family after marriage. ${ }^{9}$ At the same time fertility in Nepal is rapidly declining. In 1990, the total fertility rate (TFR) was 5.2; but had declined to 2.3 in $2016 .{ }^{10}$ Furthermore, in some urban centres, the TFR was as low as 1.4 according to the Population Census. ${ }^{11}$

Abortion in Nepal was only legalised in 2002, further facilitated by the Comprehensive Abortion Care services provided by the government from 2004, and the introduction of medical abortion in 2009. ${ }^{12} 13$ This recent legalisation means that, unlike its neighbours India and China, the use of SSA has received relatively little attention in either the research or the policy context. However, in the wake of legalisation and increasing availability of prenatal sex-determination technologies it is feared that sex-selection will spread to different sections of the population, though it has so far been concentrated among richer, more educated, urban groups. ${ }^{14}$ The Nepali context makes pervasive use of sex-selection likely as strong son preference on both religious and socioeconomic grounds paired with ongoing fertility decline means that couples feel pressure to bear a son at a low parity. Earlier studies suggested that this son preference led to women bearing more children than their preferences in order to ensure bearing a son. ${ }^{15}$ However, as the quality of antenatal care continues to improve and ultrasonography (USG), along with other prenatal sex determination technologies, becomes ever more widely available, SSA is likely to replace the strategy of having more children in order to ensure a son.

Though sex determination tests and abortion on this basis are illegal in Nepal and punishable by $3-6$ months imprisonment there is no evidence that these punishments have ever been used. Earlier studies suggest that SSA is occurring, though most evidence is either qualitative or uses small scale data. ${ }^{16}$ One qualitative study found that abortion providers find it hard to determine if the reason for abortion is sex-selection and are worried about unsafe abortion if they turn women away. ${ }^{16}{ }^{17}$ Furthermore, an estimated $58 \%$ of abortions were carried out illegally in 2014 (ie, abortions carried out by either an unapproved provider or in an unapproved facility or both), indicating the large scale potential for SSAs even if approved providers do not carry out these procedures. ${ }^{18}$ A rapid assessment prior to the legalisation of abortion in Nepal also found more male births in several districts bordering India, indicating women may have been crossing the border to receive SSAs before legalisation in Nepal. $^{17}$

There are some macrolevel correlates to skewed SRBs, such as rapid declines in fertility, patrilineal society and easy access to prenatal screening. ${ }^{4}$ A study comparing two districts in Nepal found that alongside poor enforcement of the law banning SSA, better access to ultrasound technology, fewer gender equity community programmes and the desire to have fewer children led to a higher SRB in one district. ${ }^{19}$ On the microlevel, there is strong evidence that alongside wealth, education, and region, both the number and sex of children already born plays an important role in shaping sex preferences at birth and, hence, the propensity to use SSA. A study in Kathmandu found that between 2003 and 2007 the sex ratio was skewed for second order and higher order births, however, due to small sample sizes this was not statistically significant. ${ }^{20}$ More recently, research conducted by the authors used survey data to study time trends in birth order-specific sex ratios. ${ }^{14}$ Changes in the sex ratio for the second-born child when the first-born child was female were skewed once the abortion law in Nepal changed in 2002 suggesting that SSAs are occurring. ${ }^{14}$ However, small sample sizes meant that this analysis could not estimate the prevalence or detailed subnational variation. A study in 2019 using a larger, hospital-based sample found that women having higher parity births were more likely to use sex determination tests and more unbalanced SRBs were found in second-order births compared with all births. ${ }^{21}$ This mounting evidence clearly shows that SRB are becoming skewed over time and SSAs need to be tackled before their usage spreads further. In order to do this while still ensuring wide (and increasing) access to good reproductive and maternal healthcare, further evidence and more geographically specific information about the scale and determinants of SSAs are needed.

This study, then, marks the first attempt to quantify the number of missing girls in Nepal, using the most up-to-date information from the 2011 Census and 2016 Nepal Demographic and Health Survey (DHS). As well as providing this latest information, our study presents two important additional measures. First, given what we know of the potential relationship between overall fertility levels and SSA joined with the large regional variation in fertility, this study aims to explore patterns of sex ratios and missing girls at the district and province level. Second, the study will explore so-called 'conditional' sex ratios in order to explore the microlevel determinants of sex selection. Taken together with other studies of the social context of gender bias, this information can present us with an improved understanding of the context of SSAs in Nepal and, in particular, build the evidence base required 
to implement effective policies at the national and subnational level.

\section{DATA AND METHODS \\ Data}

We use both census and survey data to provide the most comprehensive picture of SSAs and the first estimates of the scale of missing girls in Nepal. Using the full population census allows us to make estimates at the district level as the study population is so large, but as this data is now relatively dated it is also helpful to look at the extent to which the situation may have changed using the more recent DHS data.

The most recent population census in Nepal was conducted on 22 June 2011 by the Nepal Central Bureau of Statistics. ${ }^{11}$ Data collection included a full enumeration of the population, as well as age, sex and information on fertility. The decennial census is the only comprehensive source of nationally representative information on many demographic rates, which also allows detailed information to be obtained for small geographical units. Vital registration was first introduced to Nepal in 1971, but coverage remains extremely poor. ${ }^{9}$

Survey data also exists in the form of DHS, which are nationally representative surveys conducted in Nepal once every 5 years since 1996 . Within this paper, we use the full birth histories collected from women in the 2006, 2011 and 2016 rounds to estimate the changing sex ratios since 2002 in, 5-year periods. Full birth histories are collected from all women aged 15-49 in the sampled households, while background information including educational attainment and household wealth is also gathered. For more information on the DHS survey collection, please see www.dhsprogram.com. For more detail on sex ratios across earlier rounds of the DHS, please refer to previously published work, which analysed the 1996, 2001, 2006 and 2011 DHSs. ${ }^{141}$

Due to recent administrative changes, Nepal is now divided into seven provinces; these provinces were created in 2015 and thus it is not possible to compare provincial level data with previous rounds of the DHS or the census. Prior to 2015, Nepal was divided into 5 development regions and 14 zones. There were also 75 districts, of which 2 (Rukum and Nawalparasi) have been split between provinces, meaning that there are now 77 districts. In addition, the 2016 DHS is based on substantially different urban and rural classifications as compared with the 2011 DHS and population census. Fifty-nine per cent of the population is now classified as living in an urban area, compared with $17 \%$ in $2011 .{ }^{10}$ It is important to stress that this is due to reclassification of areas rather than large scale rural to urban migration. Thus, it is not possible to use the type of residence (urban or rural) variable to compare between rounds of the DHS. We have used the census to study variation by district, and the 2016 DHS to explore differences by province.

\section{Methods}

The SRB is frequently used to look for evidence of prenatal sex selection. ${ }^{22}$ The SRB is simply the ratio of males to females born, per 100 females. We note, however, that in India, the SRB is more commonly produced as the ratios of females to males per 1000 males. The SRB is a useful tool to determine evidence of SSA as it is biologically near constant aside from some diseases which can alter the chances of having a boy or girl. ${ }^{23}$ In the absence of any intervention, it should not be possible for the SRB to stray far from 105 males per 100 females and if ratios are observed that significantly exceed this number then the most likely explanation is prenatal sex selection. A further point is that from a biological perspective the sex ratio should not vary by parity or sex of previous children. However, if SSAs are occurring then it is more commonly practised after a girl or girls are born. Thus, the sex ratio of the second born child where the firstborn was female is a strong indicator of SSAs being practised and we refer to this as the conditional sex ratio (CSR). The sex ratio of third born children where the first two were female is also a good potential indicator, but sample sizes are smaller for this ratio, especially where fertility is low or falling. In Nepal, the TFR is now nearing replacement level and hence the CSR from two to three children has a much smaller sample size than for that between one and two children. The SRB was calculated for both census and DHS data, while the CSR was only calculated for DHS data. The census did not collect the full birth history of each woman, so calculating the CSR requires multiple assumptions and is not reliable.

\section{Census data}

To establish whether SSAs were likely to be occurring in each of the 75 districts, two different methods were used: 1. The SRB was calculated directly from the Census, from a question asking about births within the last 12 months. It should be noted that this question was only asked about married women aged 15-49, though, so a small number of births may have been missed (although few children are borne out of wedlock). ${ }^{24}$ To identify sex selection, we report if the SRB is significantly higher than 105 using a significance test at the $0.1 \%, 1 \%$ and $5 \%$ levels.

2. We calculated the number and percentage of missing girl births using a life table approach and the reported distribution of girls and boys aged under 5 combined with age-specific and sex-specific mortality rates. This approach has previously been used to calculate the number of missing girls using Indian Census data. ${ }^{5}$

Both approaches are subject to under-reporting of girls and girl births, while the second method is subject to additional errors as it also relies on mortality estimates. Recalling births in the last 12 months is likely to involve less recall bias as the time frame is short, thus, an SRB elevated substantially above the expected level of 105 is strong evidence that SSAs are occurring. A large number of births is needed to establish that the SRB is significantly 
above 105 unless the observed SRB is particularly high. In some districts, the number of births observed in a 12-month period was very small, so an apparently skewed SRB may not always be evidence of SSAs. Significance testing was used to account for this issue.

In order to investigate the extent to which district characteristics are associated with skewed SRBs we estimated an ordinary least squares (OLS) regression model of the district level SRB. A variety of variables that were available in the census data were studied: fertility, under 5 mortality (for males and females), population density, literacy (for males and females), percentage of Hindus, percentage of female headed households and percentage of the population that was absent. An outlier (Mustang) was identified and a dummy variable was included in order to ensure this did not affect the estimation of the coefficients, while a non-linear relationship between fertility and SRB at the district level was seen. This was solved by using the square root of fertility in the regression model.

\section{DHS data}

In order to assess if there have been changes over time and since the 2011 census the 2006, 2011 and 2016 DHSs were used. The SRB was calculated overall and for each of the seven provinces using the birth history collected from each mother, grouping births into 5-year periods (ie, 2002-2006, 2007-2011 and 2012-2016). Note that the actual periods under study conform to the Nepali calendar, which does not map onto the Western calendar perfectly. The most recent period of 2012-2016 is, roughly, April 2012-April 2016 when translated from the Nepali period of 2068-2072. CSRs were also calculated for the country and for each province from the birth history in the same periods of time, studying both the sex composition of second and third births, conditional on the composition of previous births. It should be noted that due to sample size limitations it was not possible to look at geographical units smaller than the province level. 95\% CIs were used to assess if the CSRs were different from an SRB of 105 . These CSRs and CIs were also calculated by educational level of the mother, by household wealth (as measured by the DHS wealth quintiles) and by urban/rural residence.

\section{Patient and public involvement}

This research was done without public or patient involvement.

\section{RESULTS}

\section{Population census}

The overall SRB recorded in the 2011 census was 107, which is only slightly above the expected level of 105 , though significantly so given the large number of births recorded (table 1). 11 out of 75 districts reported a significantly increased SRB of 110 or above; in each of these cases the SRB was significantly higher than 105 at the $5 \%$ significance level, while in 10 of these districts the SRB was significantly higher at the $1 \%$ level, and 7 at the $0.1 \%$ level. The SRB exceeded 115 in the districts of Kaski and 120 in Arghakhanchi and Bhaktapur. These districts were geographically spread around the country, although there are clusters in the Kathmandu Valley and across the Terai, with none in the mountainous north (figure 1A). We estimate that $2 \%$ of girl births were missing across Nepal in the 5 years before the census (figure $1 \mathrm{~B}$ and table 1 ), and $2.6 \%$ of girl births were missing in the year before the census. This equates to 22540 missing girl births across the country in the 5 years before the census,

Table 1 Sex ratios and estimated number of sex-selective abortions for Nepal and selected regions using 2011 Population Census data

\begin{tabular}{|c|c|c|c|c|c|c|}
\hline & $\begin{array}{l}\text { Sex ratio } \\
\text { at birth }\end{array}$ & $\begin{array}{l}\text { Sex ratio } \\
\text { at ages 0-4 } \\
\text { years (boys } \\
\text { per } 100 \text { girls) }\end{array}$ & $\begin{array}{l}\text { Estimated number } \\
\text { of missing girl } \\
\text { births in } 5 \text { years } \\
\text { before census }\end{array}$ & $\begin{array}{l}\text { Estimated } \\
\text { percentage of girl } \\
\text { births missing in } 5 \\
\text { years before census }\end{array}$ & $\begin{array}{l}\text { Estimated } \\
\text { percentage of girl } \\
\text { births missing in } \\
\text { year before census }\end{array}$ & $\begin{array}{l}\text { No of children } \\
0-4 \text { counted in } \\
\text { census ( } 1000 \text { s) }\end{array}$ \\
\hline Arghakhanchi & $127^{\star \star \star}$ & 113 & 609 & 6.3 & 16.4 & 21 \\
\hline Bhaktapur & $123^{\star \star \star}$ & 116 & 901 & 10.3 & 14.4 & 20 \\
\hline Gulmi & $111^{\star *}$ & 109 & 581 & 4.7 & 5.3 & 28 \\
\hline Kanchanpur & $113^{\star *}$ & 107 & 937 & 4.6 & 6.7 & 44 \\
\hline Kaski & $117^{\star \star \star}$ & 114 & 1405 & 8.7 & 9.9 & 37 \\
\hline Kathmandu & $114^{\star \star \star}$ & 114 & 4719 & 9.7 & 7.4 & 112 \\
\hline Lalitpur & $114^{\star \star \star}$ & 111 & 672 & 5.4 & 8 & 30 \\
\hline All Nepal & 107 & 105 & 22540 & 2 & 2.6 & 2568 \\
\hline
\end{tabular}

Districts shown are those with a sex ratio at birth that is significantly higher than $105,{ }^{*} 5 \%,{ }^{* *} 1 \%,{ }^{* * *} 0.1 \%$. 


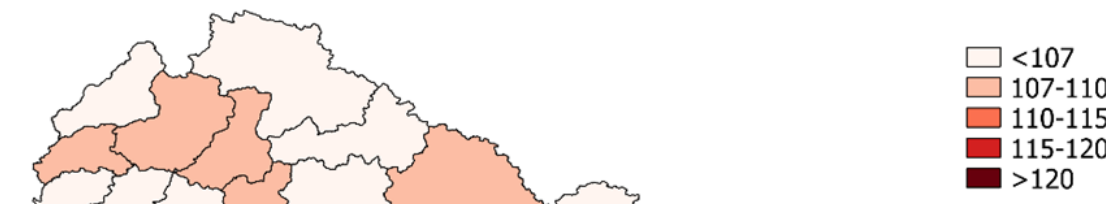

Figure 1 (A) Sex ratio at birth by district; (B) Estimated percentage of girl births missing by district. Source: 2011 population census.

6261 of which $(28 \%)$ occurred in the year before the census. This suggests that the prevalence of SSAs may be increasing over time. Particularly notable increases in the estimated percentage of missing girls over the previous year occurred in Arghakhanchi and Bhaktapur, the two districts with the highest SRBs.

There were an estimated 12076 girls missing in the eleven most affected districts; $54 \%$ of the Nepali total, indicating the geographically focused nature of the issue. In Bhaktapur we estimate that more than one in 10 girls were missing. Kathmandu was found to have the highest estimated number of SSAs, with over 4700 estimated to have occurred in the 5 years before the census (table 1). This means that roughly $20 \%$ of SSAs occurred in Kathmandu. A further 10\% occurred in Bhaktapur and Lalitpur (districts adjoining Kathmandu district, which comprise the Kathmandu Valley). In the single year before the census, we found that a higher proportion of girls was missing in virtually every district. Notably, in Arghakhanchi, we estimate that one in six girls were missing, and in Bhaktapur we estimate that one in seven were missing.
In order to understand the characteristics of districts with different SRBs, we calculated the mean of selected social and demographic characteristics from the census data within three groupings of SRB (table 2). From this, it is clear that districts with an SRB of 110 or above are markedly different from districts with a normal SRB, in that they have low fertility rates, high population density, high levels of literacy, larger percentages of Hindus and relatively low mortality. Furthermore, while the male infant mortality rate exceeds the female infant mortality rate for districts without an elevated SRB (as would be biologically expected), the female infant mortality rate exceeds the male one in districts with an elevated SRB indicating differential care practices by sex post birth, alongside sex selection during the pregnancy.

The OLS regression analysis of the same information confirms that many of these associations remain (table 3 ). The percentage of Hindus in a district and the fertility rate have a particularly strong association with the SRB. A higher proportion of Hindus is associated with a higher SRB $(p=0.004)$. Lower fertility is associated with a higher SRB ( $p=0.005)$, which supports the hypothesis that there 
Table 2 Characteristics of districts with different levels of SRB, 2011 population census

\begin{tabular}{|c|c|c|c|c|}
\hline & SRB below 107 & SRB 107-110 & $\begin{array}{l}\text { SRB } 110 \text { and } \\
\text { above }\end{array}$ & Nepal \\
\hline No of districts & 36 & 28 & 11 & 75 \\
\hline TFR & 3.1 & 3.1 & 2.1 & 2.5 \\
\hline $\begin{array}{l}\text { Female infant mortality rate as a percentage of male infant } \\
\text { mortality rate (\%) }\end{array}$ & 82 & 90 & 103 & 88 \\
\hline Female literacy (\%) & 44 & 43 & 59 & 45 \\
\hline Population density (per sq km) & 177 & 231 & 929 & 180 \\
\hline Hindu (\%) & 73 & 82 & 86 & 81 \\
\hline
\end{tabular}

SRB, sex ratios at birth; TFR, total fertility rate.

is a fertility squeeze associated with an increased propensity to have an SSA rather than simply wait to have a son. Increased population density is also associated with a higher SRB, though this association is weaker than that seen for other variables $(p=0.093)$. Population density could be a proxy for USG and/or abortion service availability, although it may also indicate wealth and education, so it is not possible to be certain what this relationship is actually measuring. The ratio of male to female under 5 mortality is also associated with the SRB ( $p=0.047)$; in this case if male mortality is lower than female mortality then the SRB is higher indicating an association between postnatal and prenatal discrimination. We also tested different specifications of the literacy variables for both males and females, including interactions, and found no evidence that these were independently associated with the SRB.

With all of these associations, it is important to be mindful of the ecological hypothesis and remember that district-level associations do not necessarily indicate individual-level associations. In the case of literacy rates where no association was found, it is also not the case that

Table 3 Linear regression model of district level sex ratio at birth, 2011 Population Census

\begin{tabular}{llrl}
\hline & Coefficient & $\mathbf{9 5 \%}$ Cl & P value \\
\hline \% Hindu & 0.09 & 0.03 to 0.15 & 0.004 \\
$\begin{array}{l}\text { Population density } \\
\text { (standardised) }\end{array}$ & 1.00 & -0.17 to 2.17 & 0.093 \\
$\begin{array}{l}\text { Square root of TFR } \\
\text { Ratio of male to }\end{array}$ & -0.97 & -10.11 to -1.82 & 0.005 \\
$\begin{array}{l}\text { female under 5 } \\
\text { mortality rates }\end{array}$ & -0.10 to 0.00 & 0.047 \\
$\begin{array}{l}\text { Dummy for } \\
\text { Mustang (outlier) }\end{array}$ & -25.63 & -33.28 to -17.97 & 0.000 \\
\hline \begin{tabular}{l} 
Constant \\
\hline
\end{tabular} & 114.83 & 106.40 to 123.27 & 0.000 \\
\hline
\end{tabular}

Manang has been excluded due to missing data.

TFR, total fertility rate. lack of association at a district level indicates a lack of individual level association; indeed our analysis of DHS data indicates that there is an association between SRBs and education. Nonetheless these results are indicative of areas that should be pursued in future research.

\section{Demographic and Health Surveys}

The results from the DHS analysis indicate that the SRB is becoming more skewed over time, with the effect being most noticeable when studying the CSRs. Table 4 shows national level CSRs at birth by parity and sex of previous children. The sex ratios of first born children and those of parity four and above are not significantly different to the level we would expect in the absence of sex selection. Looking at second born children, where we would anticipate seeing evidence of sex selection if it is being practised, the sex ratio is higher for those where the first-born child was female. Indeed, between 2012 and 2016, the sex ratio of second-born children after a first born female was 123 compared with 105 for those where the first born was male. For third-born children where the first two born were female the sex ratio was even higher at 179 . These two raised CSRs after previous female births are both significantly different from 105 . The overall SRB was estimated to be 110 in 2012-2016, but this was not significantly higher than 105 . This pattern certainly suggests that some form of prenatal sex selection against girls is occurring. The figures also suggest that this practice has likely increased over time and since the previous DHS in 2011 and the Population Census, as shown above. ${ }^{14}$

There are clear differences in the CSR of the second child where the first child was female by both educational attainment of the mother and household wealth. First, there is an educational gradient, with the highest CSR visible for women with higher education in all time periods (figure 2A). In 2002-2006, the CSR for women with higher education was 144 and by 2012-2016 it was 199. For wealth, those in the richest quintile have the highest CSR in each time period, with the exception of the second richest quintile in 2012-2016 (figure 2B). 
Table 4 Conditional sex ratios at birth (males per 100 females) by birth order, using Nepal DHS data (2006, 2011, 2016)

\begin{tabular}{|c|c|c|c|c|c|c|c|c|c|c|c|c|}
\hline \multirow{3}{*}{$\begin{array}{l}\text { Birth order } \\
\text { Sex of } \\
\text { previous } \\
\text { children } \\
\text { Year }\end{array}$} & \multicolumn{3}{|l|}{ All } & \multicolumn{3}{|c|}{ First born } & \multicolumn{6}{|c|}{ Second born } \\
\hline & \multirow[b]{2}{*}{ Mean } & \multirow[b]{2}{*}{$95 \% \mathrm{Cl}$} & \multirow[b]{2}{*}{$\mathbf{N}$} & \multirow[b]{2}{*}{ mean } & \multirow[b]{2}{*}{$95 \% \mathrm{Cl}$} & \multirow[b]{2}{*}{$\mathbf{N}$} & \multicolumn{3}{|c|}{ First-born male } & \multicolumn{3}{|c|}{ First-born female } \\
\hline & & & & & & & mean & $95 \% \mathrm{Cl}$ & $\mathbf{N}$ & mean & $95 \% \mathrm{Cl}$ & $\mathbf{N}$ \\
\hline 2002-2006 & 105 & (100 to 111$)$ & 11205 & 106 & (99 to 114 ) & 3375 & 111 & (100 to 122$)$ & 1594 & 114 & (103 to 126$)$ & 1440 \\
\hline 2007-2011 & 104 & (100 to 109$)$ & 10523 & 102 & (95 to 110$)$ & 3472 & 106 & (95 to 119 ) & 1420 & 117 & (103 to 133 ) & 1373 \\
\hline Birth order & \multicolumn{6}{|c|}{ Third born } & & & & \multicolumn{3}{|c|}{ Fourth or above } \\
\hline $\begin{array}{l}\text { Sex of } \\
\text { previous } \\
\text { children }\end{array}$ & \multicolumn{3}{|c|}{ Both male } & \multicolumn{3}{|c|}{ Both female } & \multicolumn{3}{|c|}{ One male, one female } & \multicolumn{2}{|l|}{ NA } & \\
\hline Year & Mean & $95 \% \mathrm{Cl}$ & $\mathbf{N}$ & Mean & $95 \% \mathrm{Cl}$ & $\mathbf{N}$ & Mean & $95 \% \mathrm{Cl}$ & $\mathbf{N}$ & mean & $95 \% \mathrm{Cl}$ & $\mathbf{N}$ \\
\hline
\end{tabular}

The CSR for the richest quintile decreased from 140 in 2007-2011 to 134 in 2012-2016; however, for the richer quintile the CSR increased from 102 in 2007-2011 to 156 in 2012-2016 (online supplemental file 1).

Table 5 shows regional variations at the provincial level during the 10 years preceding the 2016 Nepal DHS. The $\mathrm{SRB}$ is not significantly different from the expected value in any of the seven provinces of Nepal. However, significantly elevated CSRs can be seen in Bagmati Province $(\mathrm{CSR}=140)$ and Lumbini Province $(\mathrm{CSR}=136)$. The CSR in urban areas is 121 compared with 107 in rural areas, though the $95 \%$ CI for urban areas is 105-141. The CSR for the whole of Nepal is 115 compared with an SRB of 106, but the overall CSR is not significantly higher than the expected figure. The elevated CSRs in Bagmati and Lumbini Provinces echo the census data findings. Bagmati Province contains the Kathmandu Valley, where the largest number of SSAs were estimated to have taken place in the census data (table 1). Lumbini Province contains four districts with skewed sex ratios including Arghakhanchi, which had the highest SRB of any district according to census data in 2011 (table 1).

\section{DISCUSSION}

This study provides new evidence that there are skewed sex ratios in specific areas of Nepal. It is highly likely that these skewed ratios are caused by SSAs. However, this is not countrywide and there is a strong geographical focus: while the overall country SRB was not significantly raised, several districts showed significantly skewed SRBs at 110 or above with Kaski, Arghakhanchi and Bhaktapur having the highest SRBs. There are alternative explanations for abnormally high sex ratios, ${ }^{23}$ but these would not affect births differentially by birth order, region, or socioeconomic status so are unlikely to account for the variations in SRB that we found. As such, it is almost certain that
SSA is occurring in these districts. Over 7 million Nepalis live in districts with an SRB of 110 or above; a quarter of the population.

Previous research stated that the 2001 census showed no skewed SRBs at the district level, ${ }^{14}$ however, this study clearly shows significantly skewed SRBs in some districts in 2011, signifying an increase in SSAs in Nepal since the legalisation of abortion. We have also shown an increase in missing girls across Nepal over time and the districts with higher SRBs generally had greater increases in missing girls, again suggesting an expansion of SSAs in those particular districts.

Districts with higher SRBs had substantially different characteristics to those with normal SRBs, including lower levels of fertility, higher levels of literacy, lower mortality and a higher proportion of Hindus. This evidence supports previous research suggesting that on the macro level SSAs are most common where there is lower fertility, ${ }^{4}$ and on the microlevel among wealthier, more educated women, as well as among Hindus. This fits closely with Guilmoto's framework of 'ready, willing and able'. One study looking at two districts in Nepal found that in a district with adverse sex ratios women were more likely to be better educated, wealthier and have more equity and self-efficacy. ${ }^{19}$ In India, there is also evidence that the decision by Hindu lower to middle class women to have SSAs is based on their understanding of the economic preference for sons and their social obligation to produce a patriarchal family. ${ }^{25}$ That said, there is also some evidence in India that while increases in male education have been associated with increased SRBs, the narrowing of the female-male education gap may have reduced them. ${ }^{26}$ It also seems that as the middle classes have further expanded in India, this may have heralded a reduction in SRBs. ${ }^{26}$ However, while both Nepal and India are classed as lower-middle-income countries, India 

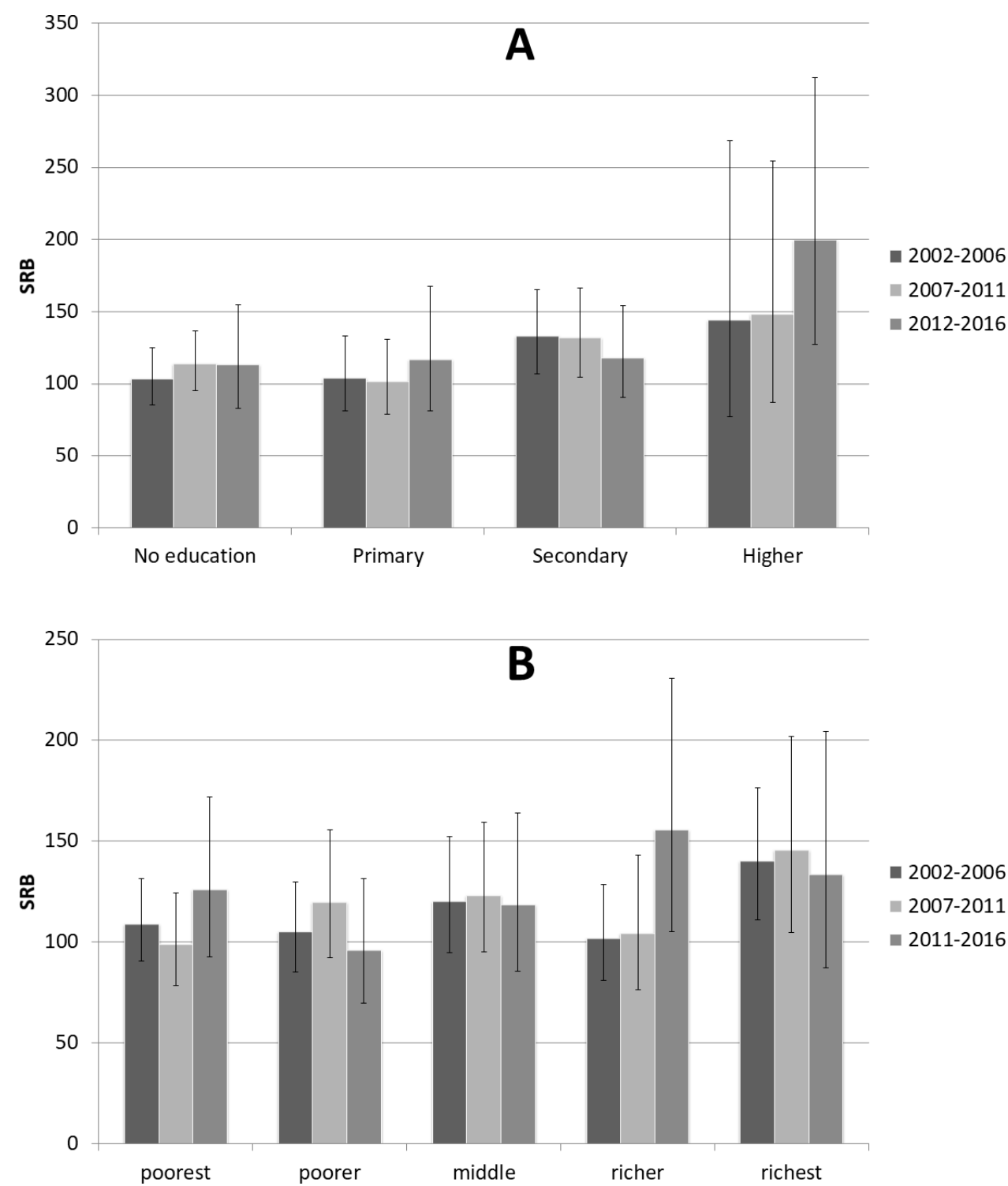

Figure 2 (A) Conditional sex ratio of second order births where the first born was female and $95 \%$ Cls, by educational level of the mother, over time; (B) Conditional sex ratio of second order births where the first born was female, by wealth quintile, over time. Source: Nepal Demographic and Health Survey's 2006, 2011 and 2016. SRB, sex ratios at birth.

has a substantially larger middle class than Nepal, with a gross national income (GNI) per capita that is twice as high. ${ }^{27}$ Therefore, a reduction in SRBs on these grounds may not be seen in Nepal.

The results from the census also found that in districts with higher SRBs the female infant mortality rate exceeded that of the male. This indicates a potential problem with discrimination against girls that are born in terms of feeding and care practices during the first year of their lives in these districts, which is something that has been observed in India. ${ }^{6}$ While it is important to note that overall mortality levels are substantially higher in districts not exhibiting evidence of SSAs, the disparity in gendered mortality rates indicates an issue that must be further researched and addressed. Girls in these districts are being discriminated against both prenatally and postnatally.
Our results are consistent with previous research on SSAs in Nepal, ${ }^{142}$ with regard to increasingly skewed sex ratios with higher birth order among women who have solely female children. Skewed SRBs are increasing over time and by area, as well as among women who have greater wealth and education. This is consistent with findings from India and Nepal in that women with more resources and knowledge have greater access to sex determination technology and are more likely to have sex determination tests, yet the use of such technologies for SSA purposes was dependent on the sex composition of their existing children. ${ }^{1421}$ The continuing trend of skewed SRBs is concerning as the long term demographic consequences are potentially severe; as these cohorts reach adulthood the 'missing females' also result in 'excess males' who struggle to marry, and some research suggests that their consequent marginalisation in a society where 
Table 5 Sex ratio at birth and conditional sex ratio of second birth when first born was female by province, 2016 Nepal DHS

\begin{tabular}{|c|c|c|c|c|c|c|}
\hline Province & CSR & $95 \% \mathrm{Cl}$ & $\mathrm{N}$ & SRB & $95 \% \mathrm{Cl}$ & $\mathrm{N}$ \\
\hline Province $1^{*}$ & 122 & (93 to 160 ) & 443 & 111 & (103 to 120$)$ & 1380 \\
\hline Province $2^{*}$ & 93 & (75 to 115 ) & 703 & 107 & (101 to 114 ) & 2313 \\
\hline Gandaki & 96 & (67 to 137 ) & 221 & 104 & (92 to 117 ) & 1057 \\
\hline Lumbini & 136 & (106 to 174 ) & 480 & 109 & (101 to 118 ) & 1718 \\
\hline Sudurpashchim & 140 & (97 to 200) & 238 & 106 & (97 to 117 ) & 1620 \\
\hline Urban & 121 & (105 to 141 ) & 909 & 105 & (99 to 111) & 6250 \\
\hline Rural & 107 & (92 to 123) & 589 & 108 & (103 to 114 ) & 4693 \\
\hline All Nepal & 115 & (103 to 128$)$ & 1498 & 106 & (102 to 111$)$ & 10943 \\
\hline
\end{tabular}

*These provinces are as yet unnamed and are currently known by their number.

CSR, conditional sex ratio; DHS, Demographic and Health Survey; SRB, sex ratios at birth .

marriage is universal may result in antisocial behaviour and violence. ${ }^{26-28}$

As fertility continues to fall, urbanisation increases, and access to prenatal sex identification technology increases it is likely that the prevalence of SSAs in Nepal will increase further. There will doubtless be a 'trickle-down' of ability to select the sex of a baby from the wealthiest and most educated as the technology becomes more widely available and more affordable. Hence without concerted effort, there is likely to be greater skewing of the sex ratio over time. It is imperative that the situation continues to be monitored, but this is challenging given that very large sample sizes are required to identify changes in the SRB. Monitoring and testing the success of any interventions are likely to be further frustrated due to the potentially delayed implementation of the next census and DHS (both scheduled in 2021) caused by the COVID-19 pandemic.

It is important to stress that the solution to this growing issue is not to ban abortion or ultrasound tests during pregnancy. Many lives have been-and continue to besaved by these policies. ${ }^{28}$ However, policy and programme responses are needed as a matter of urgency before the practice becomes any more entrenched and the sex ratio in Nepal becomes more imbalanced. Tackling SSAs requires both a demand-led and supply-led approach, bearing in mind that increases in SSAs can occur due to rising demand for them, rather than the supply of abortion services. Demand-led policies relate to lessening the preference for boys through social and political reform; while supply-led policies target the providers of prenatal screening and SSAs. There have been efforts to try to reduce the use of SSA in Nepal by lessening son preference through initiatives building gender equality and aiming to reduce gender discrimination. Such initiatives are largely introduced and run by international and national non-governmental organisations (NGOs), rather than a government-led approach. However, our research shows that SSAs are increasing and will likely continue to increase in the future due to a lack of policies, programmes and law enforcement addressing gender discrimination. ${ }^{19}$ There are also no government-led programmes focused on addressing sex selection in Nepal. Although sex determination tests and SSAs are forbidden by law in Nepal, enforcement of said laws are unregulated and do not appear to have prevented the development of an active market. A danger in supply-led only policy development, however, is that free choice and access to safe abortion services can be limited, leading to an increase in maternal mortality and morbidity. ${ }^{129}$ As such, demand-led policies may be seen as preferable. The Nepali government has a range of options to do this, bringing together a wide range of stakeholders from local authorities, policy-makers, service providers, civil society organisations and community organisations. Examples include media advocacy, legal measures to ensure gender equity such as equal inheritance and equal political representation, and social and economic incentives for vulnerable girls, such as conditional cash transfer schemes. ${ }^{30}$ In Nepal, the law is often far from equitable; for example, women can be prevented from passing citizenship onto their children, which is a source of humiliation and disempowerment. ${ }^{31}$ Ensuring that all girls are valued is a key pathway to reduce SSAs as well as enhance development in the country as a whole.

Without changing the deeply rooted discriminatory practices against women and girls in Nepal it is difficult to see how any intervention could prevent SSAs at a meaningful scale. In South Korea, efforts to decrease gender discrimination and raise the status of women have been linked to decreasing SRBs and CSRs for second and higher order births. Such efforts included more and better quality higher education and employment opportunities for women, and policies and laws focusing on women's rights and gender equity that helped to reduce the preference for sons. ${ }^{30}{ }^{32}$ Son preference was also reduced by normative change brought about through development and industrialisation, causing a natural decline of the patrilineal culture. ${ }^{7334}$ 
On this basis, the lasting solution to SSAs in Nepal is likely to be through policies and programmes that aim to empower girls, ensure gender equity and improve girls' overall situations; if underlying son preference is not tackled then efforts to reduce supply side availability of sex selection are unlikely to be successful. Furthermore, indirect interventions such as media campaigns and enforcement of the current laws to ensure gender equity in inheritance and citizenship would have positive effects on women's lives far beyond any reduction in SSAs.

Nonetheless, more efforts to raise awareness of and encourage adherence to the law among healthcare providers, including stronger monitoring mechanisms to ensure enforcement of the law and strong sanctions for the misuse of ultrasound should not be discounted. To tackle this problem it is high time Nepal developed a multisectoral national strategy and effective implementation. An analysis of the effectiveness of the PreConception and Pre-Natal Diagnostics Techniques Act that banned SSAs in India in 1996 showed a decline in child sex ratios between 1991 and 2001, arguing that the law was successful in preventing worsening gender imbalance in India. ${ }^{35}$ Additionally, in the case of South Korea, strong enforcement of sex determination and SSA laws and public awareness campaigns also significantly contributed to the reduction in SRBs, ${ }^{33}{ }^{36}$ however, such laws are far better enforced than in Nepal. ${ }^{19}$ In China, vigorous monitoring and enforcement was not enough to prevent overall increases in the SRB despite manpower and resources being employed far beyond those available to Nepal. ${ }^{30}{ }^{37}$ Thus, an increased effort to enforce the law and regulate sex determination technology should only form part of a comprehensive suite of policies aimed at tackling sex selection, though such efforts may have a positive impact if directed at the most affected districts. Increased supply-side enforcement must also never hinder women's access to ultrasound and safe abortion services.

\author{
Author affiliations \\ ${ }^{1}$ Social and Policy Sciences, University of Bath, Bath, UK \\ ${ }^{2}$ Center for Research on Environment, Health and Population Activities (CREHPA), \\ Lalitpur, Nepal \\ ${ }^{3}$ Humanities and Social Science, Hong Kong University of Science and Technology, \\ Kowloon, China \\ ${ }^{4}$ Independent Researcher, Kathmandu, Nepal \\ ${ }^{5}$ Social Statistics \& Demography, University of Southampton, Southampton, UK
}

Twitter Melanie Dawn Channon @frostyallyear, Stuart Gietel-Basten @stuartbasten and Lucy Williams Stone @LucyWStone

Contributors MDC conceptualised the study and conducted the formal analysis. MDC, MP, SG-B and AC contributed to study design. MDC, MP, LWS and AC were involved in data interpretation. MDC wrote the first draft with input from all other authors. All authors edited and revised the final manuscript. Supervision and project management were provided by MP and MDC. MDC, MP and SG-B acquired funding. All authors approved the final version.

Funding This work was supported by the Birth Control Trust of the Galton Institute, grant number R37295/GA001.

Map disclaimer The depiction of boundaries on this map does not imply the expression of any opinion whatsoever on the part of BMJ (or any member of its group) concerning the legal status of any country, territory, jurisdiction or area or of its authorities. This map is provided without any warranty of any kind, either express or implied.

Competing interests None declared.

Patient consent for publication Not required.

Ethics approval This study received ethical approval from the Central University Research Ethics Committee (CUREC) at the University of Oxford.

Provenance and peer review Not commissioned; externally peer reviewed.

Data availability statement Data are available in a public, open access repository. Demographic and Health Survey data may be obtained from the DHS Program https://dhsprogram.com/Data/. Population census data may be obtained from the Nepal Central Bureau of Statistics https://cbs.gov.np/population/.

Supplemental material This content has been supplied by the author(s). It has not been vetted by BMJ Publishing Group Limited (BMJ) and may not have been peer-reviewed. Any opinions or recommendations discussed are solely those of the author(s) and are not endorsed by BMJ. BMJ disclaims all liability and responsibility arising from any reliance placed on the content. Where the content includes any translated material, BMJ does not warrant the accuracy and reliability of the translations (including but not limited to local regulations, clinical guidelines, terminology, drug names and drug dosages), and is not responsible for any error and/or omissions arising from translation and adaptation or otherwise.

Open access This is an open access article distributed in accordance with the Creative Commons Attribution Non Commercial (CC BY-NC 4.0) license, which permits others to distribute, remix, adapt, build upon this work non-commercially, and license their derivative works on different terms, provided the original work is properly cited, appropriate credit is given, any changes made indicated, and the use is non-commercial. See: http://creativecommons.org/licenses/by-nc/4.0/.

ORCID iDs

Melanie Dawn Channon http://orcid.org/0000-0003-4820-0928

Stuart Gietel-Basten http://orcid.org/0000-0002-5818-8283

\section{REFERENCES}

1 Guilmoto CZ. The sex ratio transition in Asia. Popul Dev Rev 2009;35:519-49.

2 Zhu WX, Lu L, Hesketh T. China's excess males, sex selective abortion, and one child policy: analysis of data from 2005 national intercensus survey. BMJ 2009;338:b1211.

3 Guilmoto CZ, Hoàng X, Van TN. Recent increase in sex ratio at birth in Viet Nam. PLoS One 2009;4:e4624.

4 Guilmoto CZ. The masculinization of births. overview and current knowledge. Population 2015;70:183-243.

5 Jha P, Kesler MA, Kumar R, et al. Trends in selective abortions of girls in India: analysis of nationally representative birth histories from 1990 to 2005 and census data from 1991 to 2011. Lancet 2011;377:1921-8.

6 Gellatly C, Petrie M. Prenatal sex selection and female infant mortality are more common in India after firstborn and second-born daughters. J Epidemiol Community Health 2017;71:269-74.

7 Chung W, Gupta MD. The decline of son preference in South Korea: the roles of development and public policy. Popul Dev Rev 2007;33:757-83.

8 Brunson J. Son preference in the context of fertility decline: limits to new constructions of gender and kinship in Nepal. Stud Fam Plann 2010;41:89-98.

9 Channon M, Karki Y. Fertility preferences in Nepal. Family demography in Asia. Edward Elgar Publishing, 2018.

10 Ministry of Health - MOH/Nepal, New ERA/Nepal, ICF. Nepal demographic and health survey 2016. Kathmandu, Nepal: $\mathrm{MOH}$ / Nepal, new era, and ICF, 2017.

11 Central Bureau of Statistics. National population and housing census 2011. Kathmandu, Nepal, 2012.

12 Ministry of Health and Population, World Health Organization, Center for Research on Environment Health and Population Activities (CREHPA). Unsafe abortion: Nepal country profile. Kathmandu, Nepal, 2006.

13 Wu W-J, Maru S, Regmi K. Abortion care in Nepal, 15 years after Legalization: gaps in access, equity, and quality. Health Hum Rights 2017; 19:221.

14 Frost MD, Puri M, Hinde PRA. Falling sex ratios and emerging evidence of sex-selective abortion in Nepal: evidence from nationally 
representative survey data. BMJ Open 2013;3 doi:10.1136/ bmjopen-2013-002612

15 Stash S. Ideal-family-size and sex-composition preferences among wives and husbands in Nepal. Stud Fam Plann 1996;27:107-18.

16 Lamichhane P, Harken T, Puri M, et al. Sex-selective abortion in Nepal: a qualitative study of health workers' perspectives. Womens Health Issues 2011;21:S37-41.

17 Puri M, Adhikari R. A rapid assessment on sex ratio at birth with special reference to sex selective abortion and infanticide. Lalitpur, Nepal: UNFPA and CREHPA, 2007.

18 Puri M, Singh S, Sundaram A, et al. Abortion incidence and unintended pregnancy in Nepal. Int Perspect Sex Reprod Health 2016;42:197.

19 Puri M, Tamang A. Understanding factors influencing adverse sex ratios at birth and exploring what works to achieve balance: the situation in selected districts of Nepal. Kathmandu, Nepal: CREHPA, 2015.

20 Adhikari N, Ghimire A, Ansari I. Sex preference in urban Nepal. J Ins Med 2008;30.

21 Pradhan E, Pearson E, Puri M, et al. Determinants of imbalanced sex ratio at birth in Nepal: evidence from secondary analysis of a large hospital-based study and nationally-representative survey data. BMJ Open 2019;9:e023021.

22 Bongaarts $\mathrm{J}$. The implementation of preferences for male offspring. Popul Dev Rev 2013;39:185-208.

23 Chahnazarian A, Blumberg BS, London WT. Hepatitis B and the sex ratio at birth: a comparative analysis of four populations. J Biosoc Sci 1988;20:357-70.

24 Andersen KL, Khanal RC, Teixeira A, et al. Marital status and abortion among young women in Rupandehi, Nepal. BMC Womens Health 2015;15:17.
25 Unnithan-Kumar M. Female selective abortion-beyond 'culture': family making and gender inequality in a globalising India. Cult Health Sex 2010;12:153-66.

26 Kaur R, Bhalla SS, Agarwal MK. Sex ratio at birth: the role of gender, class and education. UNFPA, 2016.

27 GNI per capita. Atlas method (current US\$) [online], 2019. Available: https://data.worldbank.org/indicator/NY.GNP.PCAP.CD

28 Henderson JT, Puri M, Blum M, et al. Effects of abortion Legalization in Nepal, 2001-2010. PLoS One 2013;8:e64775.

29 Puri M AT. Management of abortion related complications in hospitals of Nepal-a situational analysis. Kathmandu, Nepal: CREHPA, 1999.

30 Das Gupta M. Is banning sex-selection the best approach for reducing prenatal discrimination? Asian Popul Stud 2019;15:319-36.

31 Dhamala R. Gender and citizenship in the constitution of Nepal 2015 Virginia Tech, 2019.

$32 \mathrm{~K}-\mathrm{y} \mathrm{S}$. The politics of the family law reform movement in contemporary Korea: a contentious space for gender and the nation. J Korean Stud 2006;11:93-125.

33 Hesketh T, Lu L, Xing ZW. The consequences of son preference and sex-selective abortion in China and other Asian countries. CMAJ 2011:183:1374-7.

34 Chun H, Gupta MD, eds. Gender discrimination in sex selective abortions and its transition in South Korea. Women's Studies International Forum. Elsevier, 2009.

35 Nandi A, Deolalikar AB. Does a legal ban on sex-selective abortions improve child sex ratios? Evidence from a policy change in India. J Dev Econ 2013;103:216-28.

36 Park $\mathrm{CB}$, Cho $\mathrm{N}-\mathrm{H}$. Consequences of son preference in a low-fertility Society: imbalance of the sex ratio at birth in Korea. Popul Dev Rev 1995;21:59-84.

37 Guo Z, Das Gupta M, Li S. 'Missing girls' in China and India: trends and policy challenges. Asian Popul Stud 2016;12:135-55. 